\title{
Short-term outcomes of traction-assisted versus conventional endoscopic submucosal dissection for superficial gastrointestinal neoplasms: a systematic review and meta-analysis of randomized controlled studies
}

\author{
Mengting $\mathrm{Xia}^{1+}{ }^{1+}$ Yunfeng Zhou ${ }^{2+}$, Jiajie $\mathrm{Yu}^{3}$, Wenwen $\mathrm{Chen}^{3}$, Xiaotao Huang ${ }^{1}$ and Juan $\mathrm{LiaO}^{4^{*}}$ (D)
}

\begin{abstract}
Background: In recent years, some traction-assisted approaches have been introduced to facilitate endoscopic submucosal dissection (ESD) procedures by reducing the procedure time and risks related to the procedure. However, the relative advantages of traction-assisted endoscopic submucosal dissection (T-ESD) are still being debated. This study aimed to assess the efficacy of T-ESD for the treatment of superficial gastrointestinal neoplasms.

Methods: We searched MEDLINE, Embase, and Cochrane library up to March 31, 2019 for randomized controlled trials (RCTs) comparing T-ESD and conventional endoscopic submucosal dissection (C-ESD) for superficial gastrointestinal neoplasms. The main endpoints are en bloc resection, complete resection, procedure time, perforation, and delayed bleeding. Pooled risk ratio (RR), Peto odds ratio (OR), and mean difference (MD) were calculated to compare T-ESD and C-ESD. This study is registered with PROSPERO, number CRD42018108135.

Results: A total of 7 RCTs with 1007 patients were included in this meta-analysis. There were no significant differences between the T-ESD and C-ESD groups in the pooled estimate of en bloc resection, complete resection, and delayed bleeding $\left(R R=1.00,95 \% \mathrm{Cl} 0.99,1.01, P^{2}=0 \%, P=0.66 ; \mathrm{RR}=1.00,95 \% \mathrm{Cl} 0.98,1.03\right.$, $P^{2}=0 \%, P=0.81 ; \mathrm{OR}=0.95,95 \% \mathrm{Cl} 0.48,1.86, P^{2}=19 \%, P=0.87$,respectively). The pooled estimate indicated that the procedure time was significantly shorter in the T-ESD group $(M D=-16.19,95 \% \mathrm{Cl}-29.24,-3.13$, $\left.P^{2}=87 \%, P=0.02\right)$ than in the C-ESD group. Compared to C-ESD, T-ESD was associated with lower incidence of perforation ( $\left.\mathrm{OR}=0.32,95 \% \mathrm{Cl} 0.11,0.91, P^{2}=0 \%, P=0.03\right)$.
\end{abstract}

Conclusions: T-ESD is a safe and effective treatment option with a low perforation rate and shorter procedure time than C-ESD for superficial gastrointestinal neoplasms. Future multi-center (including European populations), randomized controlled trials of larger sample size and long-term outcomes of T-ESD are required.

Keywords: Endoscopic submucosal dissection (ESD), Traction, Superficial gastrointestinal neoplasms, Meta-analysis

\footnotetext{
* Correspondence: liaojuan0606@163.com

${ }^{\dagger}$ Mengting Xia and Yunfeng Zhou are contributed equally to this work.

${ }^{4}$ Departments of Gastroenterology, West China School of Public Health and

West China Fourth Hospital, Sichuan University, 16\#, Section 3, Renmin Nan

Lu, Chengdu 610041, Sichuan, People's Republic of China

Full list of author information is available at the end of the article
}

(c) The Author(s). 2019 Open Access This article is distributed under the terms of the Creative Commons Attribution 4.0 International License (http://creativecommons.org/licenses/by/4.0/), which permits unrestricted use, distribution, and reproduction in any medium, provided you give appropriate credit to the original author(s) and the source, provide a link to the Creative Commons license, and indicate if changes were made. The Creative Commons Public Domain Dedication waiver (http://creativecommons.org/publicdomain/zero/1.0/) applies to the data made available in this article, unless otherwise stated. 


\section{Introduction}

Superficial gastrointestinal (GI) neoplasms are defined as lesions limited to the mucosa or submucosa without invading the muscularis propria, regardless of the presence of lymph node involvement. GI neoplasms include esophageal neoplasms, gastric neoplasms, duodenum neoplasms, and colorectal neoplasms. With the development and widespread implementation of endoscopic techniques, such as chromoendoscopy, magnifying endoscopy, magnifying narrow-band imaging, and confocal microscopy, the diagnosis rates of patients with superficial GI neoplasms have been increasing [1-4]. Early diagnosis and therapy of GI neoplasms will greatly improve the quality of life and survival rates. There are several treatment options for GI neoplasms, such as the endoscopic mucosal resection (EMR) [5], endoscopic submucosal dissection (ESD) [6], and surgical resection of the tumor and regional lymph nodes through laparoscopic or open operation [7].

The endoscopic treatment of EMR was initially introduced for gastric neoplasms, and subsequently, for esophageal neoplasms and colorectal neoplasms. It has been widely accepted as the standard treatment for superficial gastrointestinal neoplasms because of its minimal invasiveness. However, it is difficult to complete the en bloc resection, and this difficulty results in low curative resection and high local recurrence. To overcome this problem, ESD was developed for superficial gastrointestinal neoplasms, and it has been rapidly adopted all over the world.

However, the universal adoption of ESD has been limited by its long procedure time and high risk of complications, such as perforation and bleeding [8-10]. To improve the ESD procedure by facilitating visualization of the submucosal layer and maintaining good maneuverability, traction-assisted endoscopic submucosal dissection (T-ESD) was proposed. In 2005, Saito et al. described the traction device of the sinker system for the first time to promote the ESD procedure [11]. Recently, various strategies of traction have been developed, such as clip with line [12], external grasping forceps [13], and internal traction [14], but the efficacy of these strategies remain obscure. We, therefore, conducted this metaanalysis of randomized trials to assess the efficacy of TESD vs conventional ESD (C-ESD) for the treatment of superficial gastrointestinal neoplasms.

\section{Methods}

We followed the reporting standards set by Preferred Reporting Items for Systematic reviews and MetaAnalyses (PRISMA) [15].

\section{Eligibility criteria}

We included RCTs that included a comparison of T-ESD vs C-ESD for patients with superficial gastrointestinal neoplasms and that explicitly reported data on at least one of the outcomes: en bloc resection, complete resection, procedure time, perforation, or delayed bleeding. We excluded duplicate publications, non-English studies, and studies lacking clinical endpoints data.

\section{Literature search}

We searched MEDLINE, Embase, and Cochrane Library from inception to March 31, 2019. The search strategy combined $\mathrm{MeSH}$ terms and free-text regarding "endoscopic submucosal dissection" and "traction." Full-search strategies are provided in the Appendix. The reference list of included articles was checked to identify additional relevant studies.

\section{Study process}

A pair of reviewers (MTX and YHZ) independently screened titles/abstracts for potential eligibility and full texts for final eligibility; assessed the risk of bias; and collected data from each eligible trial using standardized, pilot tested forms. The reviewers resolved disagreements through discussion or adjudication by a third reviewer (WWC).

\section{Risk of bias of assessment}

We assessed the risk of bias of RCTs using the Cochrane tool [16], including random sequence generation, allocation concealment, blinding of participants and personnel, blinding of outcome assessment, incomplete outcome data, selective reporting, and other bias.

\section{Data extraction}

We collected the following information from each eligible RCT: study characteristics (first author, year of publication, country, and number of patients); patient characteristics (age, tumor size, and location), intervention (method of traction), and outcome data (en bloc resection, complete resection, procedure time, perforation, and delayed bleeding). Data that were reported as median (range) were converted to mean \pm SD according to the methodology of Hozo et al. [17].

\section{Statistical analysis}

RevMan 5.3 was used to analyze the data extracted from every study. We analyzed RCTs using risk ratio (RR) for dichotomous outcomes and mean difference (MD) for continuous outcomes. For the outcomes with low event rate $(<5 \%)$, we pooled data using Peto's method. We reported the pooled effects and their associated 95\% confidence intervals (CIs). A $P$ value less than 0.05 was considered statistically significant. We examined statistical heterogeneity among studies using the $I^{2}$ statistic as well as Cochrane's chi-square test. If $I^{2}>50 \%$, that 
indicated significant heterogeneity, and a random effects model was used.

For each meta-analysis, we explored sources of heterogeneity with the subgroup hypotheses: type of patient (gastric cancer vs colorectal cancer vs esophageal cancer). We tested the subgroup difference using an interaction test.

\section{Results}

\section{Study characteristics}

We identified 4423 articles by searching databases (Fig. 1) . Of these, 993 were excluded as duplicates, and 3177 articles were excluded based on the exclusion criteria. After two reviewers independently read the full text, 7 studies [18-24] with a total of 1007 patients were eventually included. The sample size of the study populations described in the included articles varied from 40 to 635 . For three of the studies, the lesions were located in the colorectum, for three studies, they were located in the stomach, and for one study, it was located in the esophagus. Six of these studies were performed in Japan, and one in Korea. The study characteristics are summarized in Table 1.

\section{Risk of bias assessment}

The risk of bias in the included studies was rigorously assessed. Of the seven RCTs, five trials [18, 19, 22-24] described the specific methods used for random sequence generation, one study [20] used the parity method, and one study [21] just mentioned "random." Three studies [19-21] concealed the treatment allocation; one study [23] did not conceal the allocation to the patients and operators, and three studies [18, 22, 24] did not mention concealment. One study [23] was not blinded to the patients and operators, and one study [22] was not blinded to the operators. In one study [18], nine patients dropped out. All of the studies avoided selective outcome reporting. Details of the methodological approach are shown in Table 2.

\section{Quantitative synthesis En bloc resection}

Six studies, including 964 patients, reported data on en bloc resection. The pooled estimate of en bloc resection on the fixed effects model indicated no significant difference in the T-ESD and C-ESD groups $(\mathrm{RR}=1.00,95 \%$ CI $\left.0.99,1.01, I^{2}=0 \%, P=0.66\right)$. There was no statistical heterogeneity (Fig. 2).

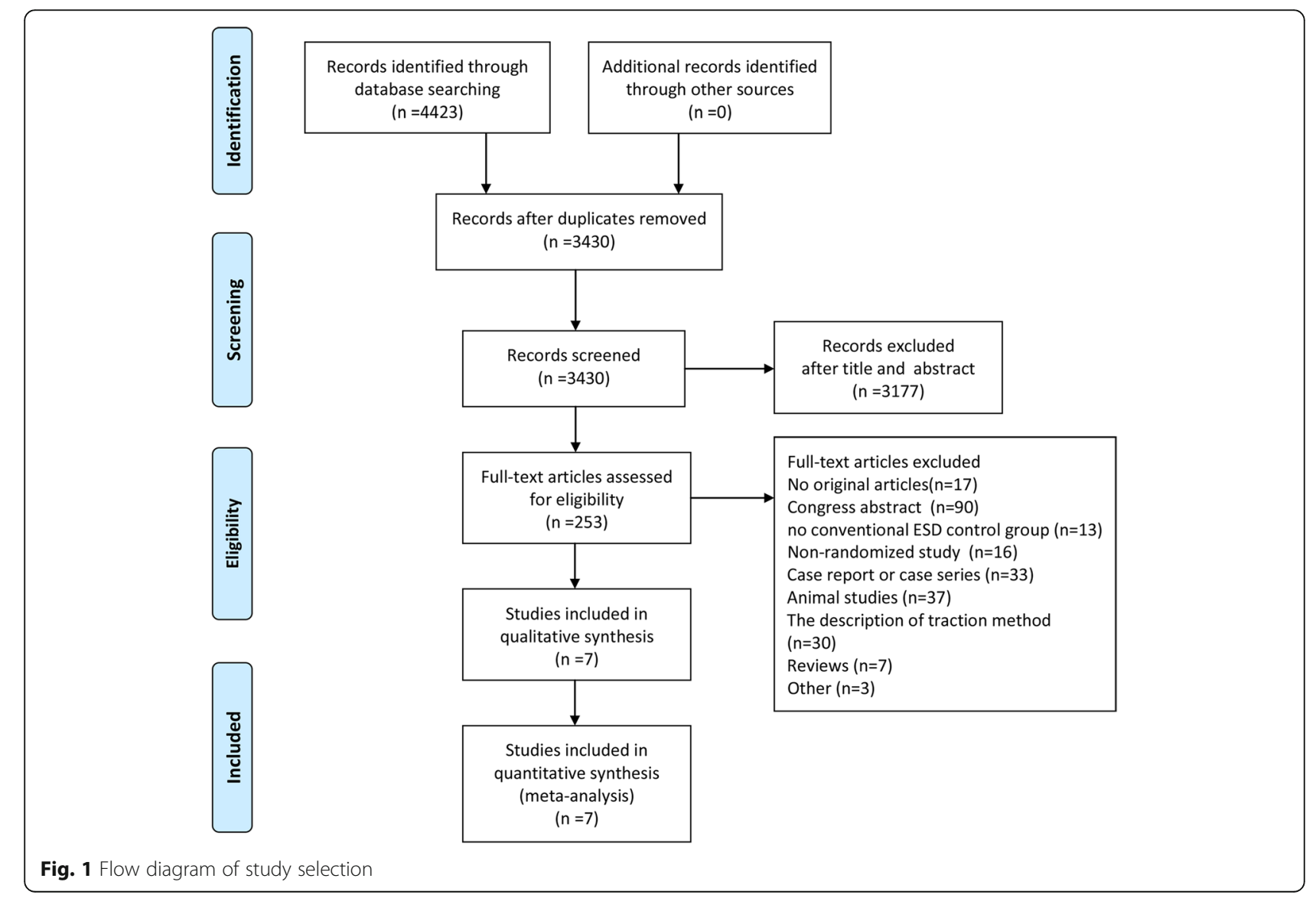


Table 1 characteristics of included studies

\begin{tabular}{|c|c|c|c|c|c|c|}
\hline $\begin{array}{l}\text { Author, year of } \\
\text { publication }\end{array}$ & Country & $\begin{array}{l}\text { Patients }(n) \\
(T-E S D \text { vs C-ESD) }\end{array}$ & $\begin{array}{l}\text { Age (years) } \\
\text { (T-ESD vs C-ESD) }\end{array}$ & Location of lesions & $\begin{array}{l}\text { Inclusion criteria for lesions size } \\
(\mathrm{mm})(\mathrm{T}-\mathrm{ESD} \text { vs C-ESD) }\end{array}$ & $\begin{array}{l}\text { Methods of } \\
\text { traction }\end{array}$ \\
\hline Ahn et al. [18] 2013 & Korea & $26: 25$ & $66.5 \pm 8.8$ vs $62.9 \pm 8.7$ & Gastric neoplasm & $20.5 \pm 7.9$ vs $19.4 \pm 6.5$ & $\begin{array}{l}\text { Transnasal } \\
\text { endoscope }\end{array}$ \\
\hline $\begin{array}{l}\text { Ritsuno et al. [21] } \\
2014\end{array}$ & Japan & $27: 23$ & $66.2 \pm 9.6$ vs $66.4 \pm 8.9$ & Colorectal tumors & $33.5 \pm 12.5$ vs $37.8 \pm 13.1$ & S-O clip \\
\hline Koike et al. [19] 2015 & Japan & $20: 20$ & $71 \pm 6.3$ vs $69.5 \pm 9.5$ & $\begin{array}{l}\text { Esophageal } \\
\text { carcinoma }\end{array}$ & $24(11-92)$ vs $27(8-48)$ & $\begin{array}{l}\text { Clip with } \\
\text { thread }\end{array}$ \\
\hline Mori et al. [20] 2017 & Japan & $21: 22$ & $74 \pm 10$ vs $72 \pm 12$ & Colorectal tumors & NA & $\begin{array}{l}\text { Ring-shaped } \\
\text { thread }\end{array}$ \\
\hline $\begin{array}{l}\text { Yamasaki et al. [22] } \\
2018\end{array}$ & Japan & $42: 42$ & $65(41-84)$ vs $67(43-86)$ & Colorectal neoplasm & $30(20-55)$ vs $30(20-60)$ & Clip-and-thread \\
\hline $\begin{array}{l}\text { Yoshida et al. [23] } \\
2018\end{array}$ & Japan & $319: 316$ & $70.2 \pm 9.4$ vs $71 \pm 8.4$ & Gastric neoplasms & $15.7 \pm 10.1$ vs $15.5 \pm 8.9$ & Dental floss clip \\
\hline Ban et al. [24] 2018 & Japan & 49:55 & $71.2 \pm 6.5$ vs $69.0 \pm 9.5$ & $\begin{array}{l}\text { Gastric cancers or } \\
\text { gastric adenomas }\end{array}$ & NA & Clip-flap \\
\hline
\end{tabular}

$T$-ESD traction-assisted endoscopic submucosal dissection; C-ESD conventional endoscopic submucosal dissection; NA not available

Age and size of lesions was expressed with (mean \pm SD) or median (range)

\section{Complete resection}

Three studies, including 770 patients, reported complete resection. The pooled estimate of complete resection on the fixed effects model indicated no significant difference in the T-ESD and C-ESD groups $(\mathrm{RR}=1.00,95 \%$ CI $\left.0.98,1.03, I^{2}=0 \%, P=0.81\right)$. There was no statistical heterogeneity (Fig. 3).

\section{Procedure time}

The procedure time was reported in all studies, including 1007 patients. The pooled estimate on the random effects model indicated that the procedure time was significantly shorter in the T-ESD group than in the C-ESD group (MD $=-16.19,95 \%$ CI -29.24 , $\left.3.13, I^{2}=87 \%, P=0.02\right)$. The heterogeneity was significant (Fig. 4).

\section{Perforation}

Perforation data were reported in all studies, including 1007 patients.

After the studies were removed, in which the incidence of both groups was 0 , we finally pooled estimate 5 studies including 916 patients. Perforation was observed in 3 of
458 patients in the T-ESD group and in 11 of 458 patients in the C-ESD group. When the data were pooled, there was a significant difference in the incidence of perforation between the two groups. Compared to C-ESD, T-ESD was associated with lower incidence of perforation $(\mathrm{OR}=0.32$, $95 \%$ CI $\left.0.11,0.91, I^{2}=0 \%, P=0.03\right)$. There was no statistical heterogeneity (Fig. 5).

\section{Delayed bleeding}

All studies reported the incidence of delayed bleeding including 1007 patients. After the studies were removed, in which the incidence of both groups was 0 , we finally pooled estimate four studies including 833 patients. The pooled estimate on the fixed effect model indicated no significant difference in delayed bleeding between the two groups $\left(\mathrm{OR}=0.95\right.$, 95\% CI $0.48,1.86, I^{2}=19 \%, P=$ 0.87 ). There was slight statistical heterogeneity (Fig. 6).

\section{Subgroup analysis}

Because studies evaluating patients with lesions in different locations were combined in the present meta-analysis, we performed a subgroup analysis according to the lesion location: gastric neoplasms, colorectal neoplasms, and

Table 2 The risk of bias of the included studies

\begin{tabular}{|c|c|c|c|c|c|c|c|}
\hline Author & $\begin{array}{l}\text { Random sequence } \\
\text { generation }\end{array}$ & $\begin{array}{l}\text { Allocation } \\
\text { concealment }\end{array}$ & $\begin{array}{l}\text { Blinding of participants } \\
\text { and personnel }\end{array}$ & $\begin{array}{l}\text { Blinding of outcome } \\
\text { assessment }\end{array}$ & $\begin{array}{l}\text { Incomplete } \\
\text { outcome data }\end{array}$ & $\begin{array}{l}\text { Selective } \\
\text { reporting }\end{array}$ & $\begin{array}{l}\text { Other } \\
\text { bias }\end{array}$ \\
\hline Ahn et al. [18] 2013 & Low risk & Unclear & Unclear & Unclear & High risk & Low risk & Low risk \\
\hline Ritsuno et al. [21] 2014 & Unclear & Low risk & Unclear & Unclear & Low risk & Low risk & Low risk \\
\hline Koike et al. [19] 2015 & Low risk & Low risk & Unclear & Unclear & Low risk & Low risk & High risk \\
\hline Mori et al. [20] 2017 & Unclear & Low risk & Unclear & Unclear & Low risk & Low risk & Unclear \\
\hline Yamasaki et al. [22] 2018 & Low risk & Unclear & High risk & Unclear & Low risk & Low risk & Unclear \\
\hline Yoshida et al. [23] 2018 & Low risk & High risk & High risk & Unclear & Low risk & Low risk & Unclear \\
\hline Ban et al. [24] 2018 & Low risk & Unclear & Unclear & Unclear & Low risk & Low risk & High risk \\
\hline
\end{tabular}




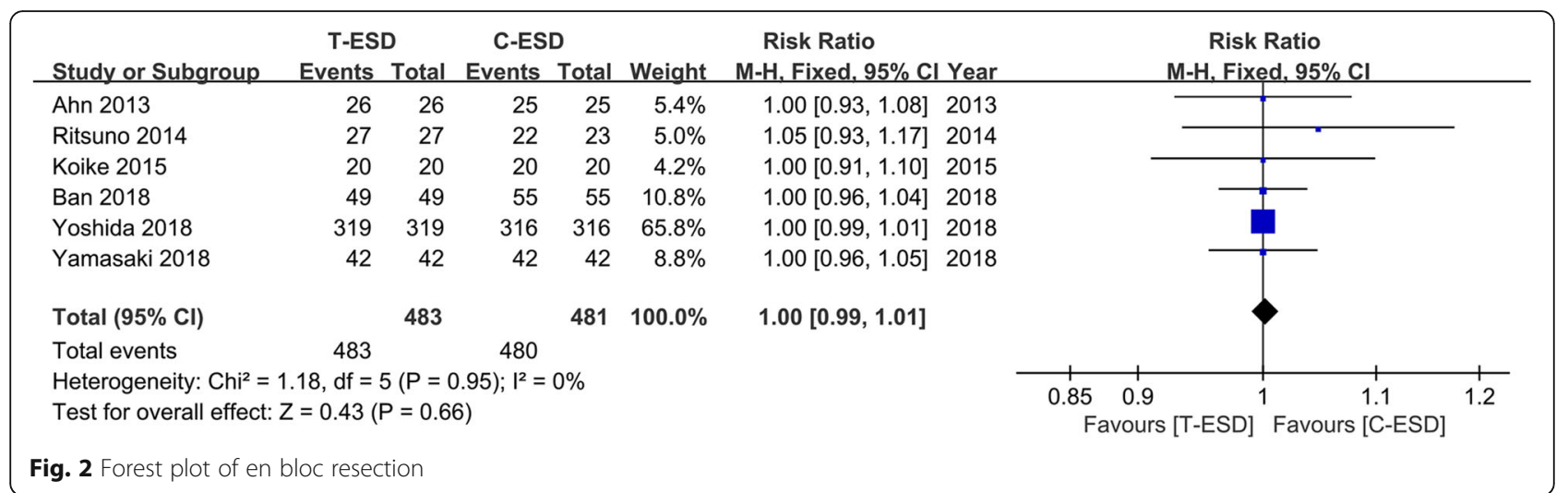

esophageal neoplasms. The pooled estimate of procedure time demonstrated that there was no significant difference between the T-ESD and C-ESD groups in the gastric neoplasms group $\left(\mathrm{MD}=-0.25,95 \% \mathrm{CI}-5.5,5.01, I^{2}=0 \%\right.$, $P=0.93$ ), while in colorectal neoplasms, the procedure time was significantly shorter in the T-ESD group than in the C-ESD group (MD $=-37.94,95 \% \mathrm{CI}-54.82,-21.05$, $\left.I^{2}=60 \%, P<0.0001\right)$. Heterogeneity was still significant. Only one study in the esophageal neoplasms group suggested that there was no statistically significant difference between the T-ESD and C-ESD groups (Fig. 7).

We performed a sensitivity analysis and removed one study at a time, but the heterogeneity did not change significantly.

\section{Discussion}

This systematic review and meta-analysis compare $\mathrm{T}$ ESD to C-ESD. The pooled results demonstrate that TESD and C-ESD were similarly effective in en bloc resection, complete resection, and delayed bleeding. However, we provide evidence that T-ESD has significant advantages in that it is associated with a lower incidence of perforation. During the operation, traction technology can effectively reduce the operation time.

ESD has become the first-line treatment of superficial gastrointestinal neoplasms with high en bloc resection and curative resection rates. The safety of the ESD process is especially important in a variety of clinical situations. According to National Cancer Center Hospital of Japan [25], delayed bleeding occurred in $6 \%$ of patients; perforation is the complication of greatest concern, and it occurred in 3\% of patients during the ESD procedure. In addition to the operator's experience, a poor visual field of the cutting line can result in deeper tissue and submucosal vessels being vulnerable to injury and may be associated with a high risk of complication. Our study suggests that a traction system that facilitates direct visualization of the submucosal layer is effective for reducing the incidence of perforation. The study of Xie et al. [26] showed T-ESD to be beneficial for preventing muscular layer injury. This conclusion potentially confirms our result.

Previously, most studies in humans and animals have indicated that T-ESD is an appropriate alternative for CESD with shorter time [26-29]. Our study supports this finding. However, there is substantial heterogeneity in the outcome of procedure time. In the included studies, three articles concern colorectal neoplasms, three concern gastric neoplasms, and one concerns esophageal neoplasms, which may be a selection bias based on the anatomical characteristics. We know the difficulty level varies based on the location of lesions. Considering the differences in blood vessel size, fat levels, and angles, even in the same portion of the stomach, the degree of difficulty greatly differs [30]. For colorectal neoplasms, it is clear that the proximal colon is a more difficult location than

\begin{tabular}{|c|c|c|c|c|c|c|c|}
\hline Study or Subgroup & $\begin{array}{l}\text { T-ES } \\
\text { Events }\end{array}$ & Total & $\begin{array}{l}\text { C-ES } \\
\text { Events }\end{array}$ & $\begin{array}{l}\text { D } \\
\text { Total }\end{array}$ & Weight & $\begin{array}{l}\text { Risk Ratio } \\
\text { M-H, Fixed, } 95 \% \text { Cl Year }\end{array}$ & $\begin{array}{c}\text { Risk Ratio } \\
\text { M-H, Fixed, } 95 \% \mathrm{Cl}\end{array}$ \\
\hline Ahn 2013 & 25 & 26 & 24 & 25 & $6.6 \%$ & $1.00[0.90,1.12] 2013$ & \\
\hline Yoshida 2018 & 312 & 319 & 306 & 316 & $82.4 \%$ & $1.01[0.98,1.04] 2018$ & \\
\hline Yamasaki 2018 & 39 & 42 & 41 & 42 & $11.0 \%$ & $0.95[0.86,1.05] 2018$ & \\
\hline Total $(95 \% \mathrm{Cl})$ & & 387 & & 383 & $100.0 \%$ & $1.00[0.98,1.03]$ & \\
\hline Total events & 376 & & 371 & & & & \\
\hline $\begin{array}{l}\text { Heterogeneity: } \mathrm{Chi}^{2}= \\
\text { Test for overall effect }\end{array}$ & $\begin{array}{l}1.45, \mathrm{df}=2 \\
Z=0.24(\mathrm{~F}\end{array}$ & $\begin{array}{l}(P=0 \\
=0.8\end{array}$ & 1) 49$) ; 1^{2}=$ & $0 \%$ & & & 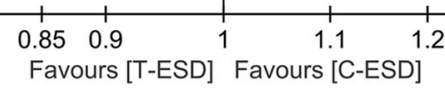 \\
\hline
\end{tabular}




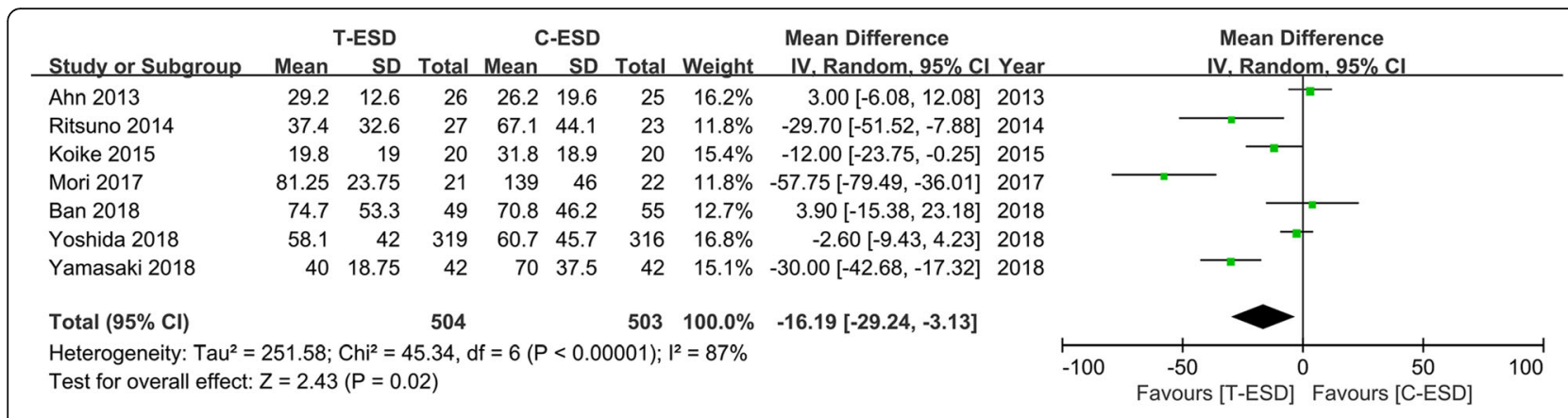

Fig. 4 Forest plot of procedure time

the rectum and requires longer operation time. In the included studies of our meta-analysis, the difference of operator's experience may be related to procedure time and result in a significant heterogeneity. Furthermore, differences in devices and equipment such as in the endoscope, knife, and traction method may be associated with heterogeneity to some degree.

Due to the complexity of ESD, the success of ESD procedure depends to some extent on abundant endoscopic experience and on the skill of endoscopist. Gotoda et al. [31] reported that at least 40 ESD procedures are needed for a trainee endoscopist to overcome the learning curve and gain proficiency in this technique. Operators who lack of ESD experience will lead to higher incidence of procedural complications such as bleeding and perforation. In addition, considering the anatomical characteristics of different organs, the complications are related to patient groups with the lesions located in different locations. The esophageal diameter is narrower than other organs, the stomach is a J-shaped organ that can appear various shapes with peristalsis and is divided into five areas: the cardia, the fundus, the body, the antrum, and the pylorus, the colorectum with thin intestinal wall and small angulated lumen. When the lesions are located in easy-to-operate locations such as the rectum and the lower part of the stomach, there will be fewer complications than in other locations. Therefore, it is important to evaluate the effect of ESD and traction methods according to the lesion location.

To obtain better visibility, a variety of traction methods have been applied to facilitate the ESD procedures, such as the clip with line method [12], the magnetic anchor method [32], the double-endoscope method [33], the internal traction method $[14,30]$, and the external grasping forceps method [13]. However, each method has its own advantage and disadvantage. The clip with line is simple and helpful in almost all gastrointestinal neoplasms, but the direction of traction is limited, and the endoclip is easily detached from the specimen. For magnetic anchor ESD, the direction and degree of traction can be easily controlled by changing the location of the external magnet. The disadvantages of this traction method are that the strength is attenuated with the amount of abdominal fat and the internal magnet requires additional coating to prevent damage to the human body. The double-scope technique can adjust the direction of traction by maneuvering the endoscope, changing the angle, and inserting or retracting the grasping forceps. However, this method still has shortcomings. First, two endoscopes will interfere with each other. Second, this method requires adequate space for the placement of two light sources and the occurrence of optical interference. The internal traction includes several methods, such as S-O clip, medical ring, clip modifications, rubber strips, and clip-band. This technique can

\begin{tabular}{|c|c|c|c|c|c|c|c|c|c|c|c|}
\hline Study or Subgroup & $\begin{array}{l}\text { T-ESD } \\
\text { Events }\end{array}$ & Total & $\begin{array}{l}\text { C-ES } \\
\text { Events }\end{array}$ & $\begin{array}{l}\text { D } \\
\text { Total }\end{array}$ & Weight & $\begin{array}{l}\text { Peto Odds Ratio } \\
\text { Peto, Fixed, } 95 \% \text { C }\end{array}$ & Year & & $\begin{array}{l}\text { Peto Odc } \\
\text { Peto, Fixe }\end{array}$ & $\begin{array}{l}\text { ds Ratio } \\
\text { ed, } 95 \% \mathrm{Cl}\end{array}$ & \\
\hline Ritsuno 2014 & 0 & 27 & 1 & 23 & $7.2 \%$ & $0.11[0.00,5.80]$ & 2014 & & & & \\
\hline Mori 2017 & 0 & 21 & 1 & 22 & $7.2 \%$ & $0.14[0.00,7.15]$ & 2017 & & & & \\
\hline Ban 2018 & 1 & 49 & 1 & 55 & $14.2 \%$ & $1.12[0.07,18.30]$ & 2018 & & & & \\
\hline Yoshida 2018 & 1 & 319 & 7 & 316 & $57.1 \%$ & $0.22[0.05,0.88]$ & 2018 & & D & & \\
\hline Yamasaki 2018 & 1 & 42 & 1 & 42 & $14.3 \%$ & $1.00[0.06,16.26]$ & 2018 & & & & \\
\hline Total $(95 \% \mathrm{Cl})$ & & 458 & & 458 & $100.0 \%$ & $0.32[0.11,0.91]$ & & & & & \\
\hline Total events & 3 & & 11 & & & & & & & & \\
\hline $\begin{array}{l}\text { Heterogeneity: } \text { Chi }^{2}= \\
\text { Test for overall effect: }\end{array}$ & $\begin{array}{l}15, \mathrm{df}=4 \\
=2.14(\mathrm{P}\end{array}$ & $\begin{array}{l}4(P=0 \\
=0.03\end{array}$ & 3) & $0 \%$ & & & & 0.01 & $\begin{array}{c}0.1 \\
\text { Favours [T-ESD] }\end{array}$ & $\begin{array}{cc}1 & 10 \\
\text { Favours [C-ESD] }\end{array}$ & ${ }_{100}$ \\
\hline
\end{tabular}




\begin{tabular}{|c|c|c|c|c|c|c|c|c|c|c|c|}
\hline Study or Subgroup & $\begin{array}{l}\text { T-ESD } \\
\text { Events }\end{array}$ & Total & $\begin{array}{l}\text { C-ES } \\
\text { Events }\end{array}$ & Total & Weight & $\begin{array}{l}\text { Peto Odds Ratio } \\
\text { Peto, Fixed, } 95 \% \mathrm{Cl}\end{array}$ & Year & & $\begin{array}{r}\text { Peto Odd } \\
\text { Peto. Fixec }\end{array}$ & $\begin{array}{l}\text { Is Ratio } \\
\text { d. } 95 \% \mathrm{Cl}\end{array}$ & \\
\hline Ahn 2013 & 2 & 26 & 0 & 25 & $5.8 \%$ & $7.40[0.45,121.76]$ & 2013 & & & & \\
\hline Mori 2017 & 0 & 21 & 1 & 22 & $3.0 \%$ & $0.14[0.00,7.15]$ & 2017 & $\leftarrow$ & & & \\
\hline Yoshida 2018 & 14 & 319 & 14 & 316 & $79.7 \%$ & $0.99[0.46,2.11]$ & 2018 & & & & \\
\hline Ban 2018 & 1 & 49 & 3 & 55 & $11.5 \%$ & $0.40[0.05,2.94]$ & 2018 & & & & \\
\hline Total $(95 \% \mathrm{Cl})$ & & 415 & & 418 & $100.0 \%$ & $0.95[0.48,1.86]$ & & & & & \\
\hline Total events & 17 & & 18 & & & & & & & & \\
\hline \multicolumn{8}{|c|}{$\begin{array}{l}\text { Heterogeneity: } \mathrm{Chi}^{2}=3.70, \mathrm{df}=3(P=0.30) ; I^{2}=19 \% \\
\text { Test for overall effect: } Z=0.16(P=0.87)\end{array}$} & 0.01 & $\begin{array}{l}0.1 \\
\text { Favours }[T-E S D]\end{array}$ & $\begin{array}{c}10 \\
\text { Favours }[\mathrm{C}-\mathrm{ESD}]\end{array}$ & 100 \\
\hline
\end{tabular}

apply to any direction, but it is difficult to control the traction direction and requires special devices and equipment. Through external grasping forceps method, the direction of traction can be easily adjusted by pushing and pulling the forceps, and no assistant is required to hold the forceps during the ESD procedure. However, the forceps are not flexible, and it is sometimes difficult to anchor the distal edge of the lesion. Hence, future randomized clinical trials comparing the different traction techniques are warranted to help define the suitable traction method for different locations.

Several limitations are presented in this study. First, we included seven articles in English, six of them from Japan and one from Korea, so generalizing the results to other races should be done with caution. Second, the number of included studies is limited, and most of them are small samples. The only study with a large sample size accounts for a large weight in Figs. 2, 3, 5, and 6, so the credibility of the result may be affected. Third, due to the features of the operative procedure, the risk of failure to apply blinding should be considered. Fourth, we could not separately evaluate a particular traction technique because the selected trials used different traction methods. Fifth, due to the high success rate of en bloc resection and complete resection in the ESD procedure, we cannot get a meaningful conclusions. Therefore, we expect that there will be more large sample studies to focus on en bloc resection and complete resection in the future. Finally, the analysis of the longterm oncological outcomes were not available due to the lack of insufficient information.

\section{Conclusion}

This systematic review and meta-analysis demonstrate the traction-assisted endoscopic submucosal dissection is superior to conventional ESD for Asians with superficial gastrointestinal neoplasms. Traction ESD effectively reduces the perforation rate and shortens the operation

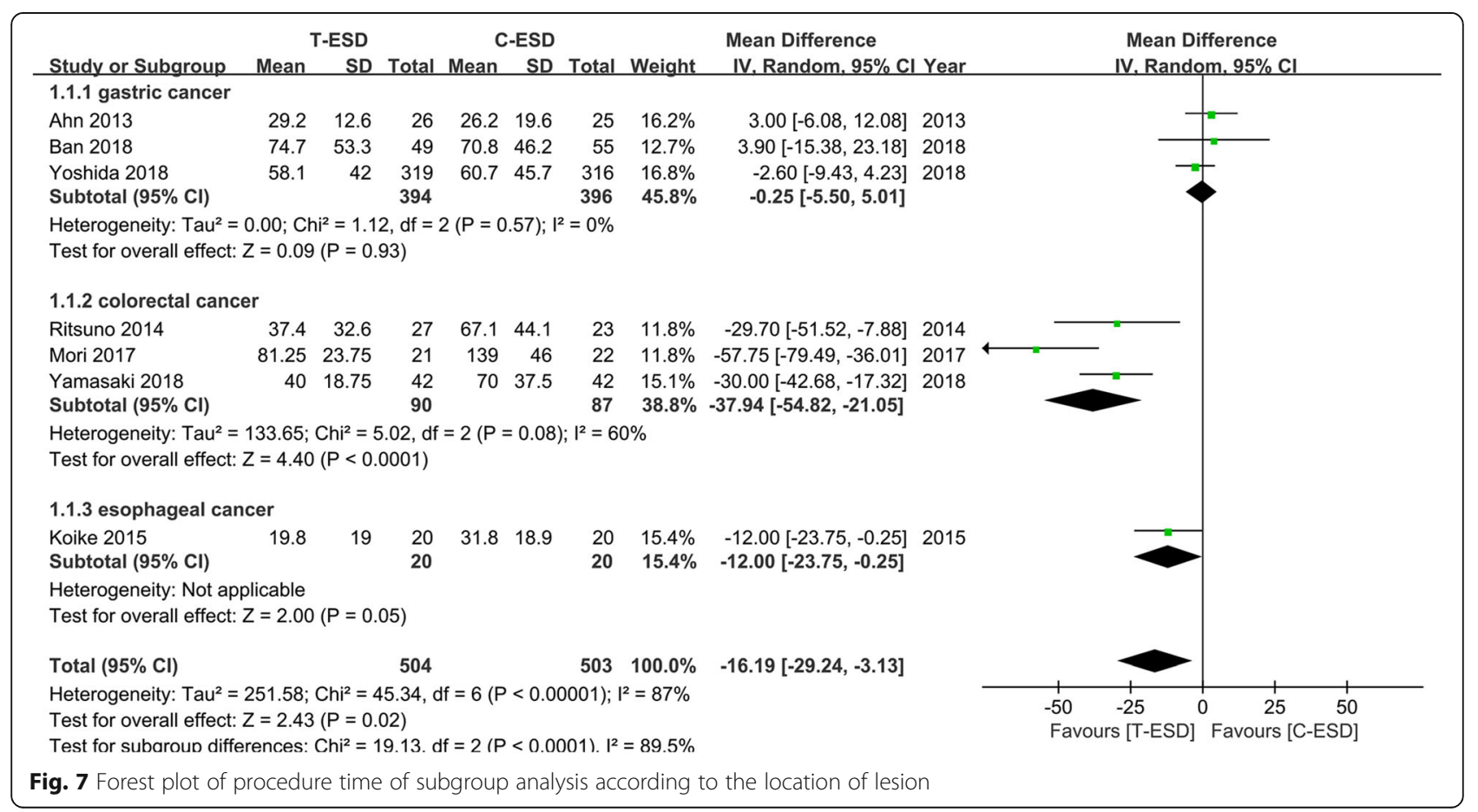


time. Future multi-center (including European populations), randomized controlled trials of larger sample size and long-term outcomes of T-ESD are awaited to further firm the conclusion.

\section{Appendix}

Embase:

\#1 'endoscopic submucosal dissection'/exp. OR 'Submucosal Dissection":ti,ab OR 'endoscopic Dissection"'ti, ab OR 'endoscopic mucosal dissection"':ti,ab OR 'Dissection*, Endoscopic Submucosal':ti,ab OR 'Endoscopic Submucosal Dissection"'ti,ab OR 'Submucosal Dissection*, Endoscopic':ti,ab OR ESD:ti,ab

\#2 Pull":ti,ab OR Drag*:ti,ab OR Haul":ti,ab OR tow*:ti, ab OR traction:ti,ab OR guid":ti,ab

\#3 Clip":ti,ab OR Hemoclip":ti,ab OR endoclip":ti,ab OR thread":ti,ab OR string*:ti,ab OR snare*:ti,ab OR magnetic:ti,ab OR Anchor*:ti,ab OR sinker*:ti,ab OR band":ti,ab OR robot*:ti,ab OR EndoLifter*:ti,ab OR pulley":ti,ab OR Spring":ti,ab OR 'dental floss"'ti,ab OR (external NEAR/2 forcep*):ti,ab OR 'internal traction':ti, ab OR pre-looping OR prelooping OR 'suture material': ti,ab OR (double NEAR/2 scope):ti,ab OR 'transnasal endoscope':ti,ab OR (percutaneous NEAR/2 traction):ti, ab OR 'endoscopic surgical platform':ti,ab OR 'steerable grasper"':ti,ab OR 'retraction strip"':ti,ab OR 'medical ring"':ti,ab OR (robotic NEAR/2 manipulator):ti,ab OR 'cross-counter technique':ti,ab

\#4 \#2 OR \#3

\#5 \#1 AND \#4

PubMed

\#1 "Submucosal Dissection"[Title/Abstract] OR "Submucosal Dissections"[Title/Abstract] OR "endoscopic Dissection"[Title/Abstract] OR "endoscopic Dissections"[Title/ Abstract] OR "endoscopic mucosal dissection"[Title/Abstract] OR "endoscopic mucosal dissections" [Title/Abstract] OR "Dissection, Endoscopic Submucosal"[Title/Abstract] OR “Dissections, Endoscopic Submucosal"[Title/Abstract] OR "Endoscopic Submucosal Dissection"[Title/Abstract] OR "Endoscopic Submucosal Dissections"[Title/Abstract] OR "Submucosal Dissection, Endoscopic"[Title/Abstract] OR "Submucosal Dissections, Endoscopic"[Title/Abstract] OR ESD[Title/Abstract]

\#2 Pull*[Title/Abstract] OR Drag*[Title/Abstract] OR Haul*[Title/Abstract] OR tow*[Title/Abstract] OR traction[Title/Abstract] OR guided[Title/Abstract] OR guidance[Title/Abstract] OR guide[Title/Abstract]

\#3 Clip*[Title/Abstract] OR Hemoclip*[Title/Abstract] OR endoclip*[Title/Abstract] OR "dental floss""[Title/Abstract] OR "external forcep"”[Title/Abstract] OR "external grasping forcep*" [Title/Abstract] OR "internal traction"[Title/Abstract] OR "Thread" traction"[Title/Abstract] OR string*[Title/Abstract] OR snare*[Title/Abstract] OR prelooping[Title/Abstract] OR prelooping[Title/Abstract] OR "suture material"[Title/Abstract] OR "double scope"[Title/ Abstract] OR "double channel scope"[Title/Abstract] OR "transnasal endoscope"[Title/Abstract] OR magnetic[Title/ Abstract] OR Anchor"[Title/Abstract] OR "percutaneous traction"[Title/Abstract] OR "percutaneous transgastric traction"[Title/Abstract] OR sinker"[Title/Abstract] OR band"[Title/Abstract] OR "endoscopic surgical platform"[Title/Abstract] OR "ring thread" "[Title/Abstract] OR "ring shaped thread"”[Title/Abstract] OR "steerable grasper"”[Title/Abstract] OR "retraction strip" "[Title/Abstract] OR "medical ring"" [Title/Abstract] OR "robotic suture manipulator"[Title/Abstract] OR "robotic manipulator"[Title/Abstract] OR EndoLifter"[Title/Abstract] OR Spring*[Title/ Abstract] OR "cross-counter technique"[Title/Abstract] OR pulley"[Title/Abstract] OR robot"[Title/Abstract]

\#4 \#2 OR \#3

\#5 \#1 AND \#4

Cochrane

\#1 Submucosal Dissection":ti,ab,kw or endoscopic Dissection":ti,ab,kw or endoscopic mucosal dissection":ti,ab, kw or Dissection*, Endoscopic Submucosal:ti,ab,kw or Endoscopic Submucosal Dissection*:ti,ab,kw or Submucosal Dissection*, Endoscopic:ti,ab,kw or ESD:ti,ab,kw

\#2 Pull*:ti,ab,kw or Drag":ti,ab,kw or Haul*:ti,ab,kw or tow":ti,ab,kw or traction:ti,ab,kw or guid":ti,ab,kw

\#3 Clip*:ti,ab,kw or Hemoclip*:ti,ab,kw or endoclip*:ti, $a b, k w$ or string*:ti,ab,kw or snare*ti,ab,kw or prelooping:ti,ab,kw or prelooping:ti,ab,kw or magnetic:ti,ab, kw or Anchor*:ti,ab,kw or sinker*:ti,ab,kw or band":ti,ab, kw or EndoLifter":ti,ab,kw or Spring":ti,ab,kw or pulley*: ti,ab,kw or robot":ti,ab,kw or "dental floss":ti,ab,kw or "external forcep":ti,ab,kw or "external grasping forcep"”: ti,ab,kw or "internal traction":ti,ab,kw or "Thread" traction":ti,ab,kw or "suture material":ti,ab,kw or "double scope":ti,ab,kw or "double channel scope":ti,ab,kw or "transnasal endoscope":ti,ab,kw or "percutaneous traction":ti,ab,kw or "percutaneous transgastric traction":ti, $\mathrm{ab}, \mathrm{kw}$ or "endoscopic surgical platform":ti,ab,kw or "ring thread"”:ti,ab,kw or "ring shaped thread":ti,ab,kw or "steerable grasper" or "medical ring":ti,ab,kw or "robotic suture manipulator":ti,ab,kw or "robotic manipulator":ti,ab,kw or "crosscounter technique":ti,ab,kw

\#4 \#2 OR \#3

\#5 \#1 AND \#4

\section{Abbreviations}

C-ESD: Conventional endoscopic submucosal dissection; EMR: Endoscopic mucosal resection; ESD: Endoscopic submucosal dissection; Gl: Superficial gastrointestinal; RCTs: Randomized controlled trials; T-ESD: Traction-assisted endoscopic submucosal dissection

Acknowledgements

Not applicable. 


\section{Authors' contributions}

MTX, YFZ, and JL conceived and designed the study. WWC and XTH performed the literature search. MTX, YFZ, JJY, and WWC collected, analyzed, and interpreted the data. MTX and YFZ wrote the first draft of the manuscript. $J L$ and $J J Y$ revised it critically for important intellectual content. All authors read and approved the final manuscript.

\section{Funding}

This work was supported by the Nanchong Municipality-University Strategic Cooperative Science and Technology Project (project no. 18SXHZ0255).

We assure this funding will not be used for some other purposes except this meta-analysis.

\section{Availability of data and materials}

All data generated or analyzed during this study are included in this published article.

\section{Ethics approval and consent to participate}

All analyses were based on previous published studies; thus, no ethics approval/written consent are required.

\section{Consent for publication}

All analyses were based on previous published studies; thus, no consent for publication is required.

\section{Competing interests}

The authors declare that they have no competing interests.

\section{Author details}

'Department of Gastroenterology, Affiliated Hospital of North Sichuan Medical College, Nanchong, Sichuan, China. ${ }^{2}$ Departments of Thoracic Surgery, West China School of Public Health and West China Fourth Hospital, Sichuan University, Chengdu, Sichuan, People's Republic of China. ${ }^{3}$ Chinese Evidence-Based Medicine Center, West China Hospital, Sichuan University, Chengdu, Sichuan, China. ${ }^{4}$ Departments of Gastroenterology, West China School of Public Health and West China Fourth Hospital, Sichuan University, 16\#, Section 3, Renmin Nan Lu, Chengdu 610041, Sichuan, People's Republic of China.

\section{Received: 12 January 2019 Accepted: 27 May 2019}

\section{Published online: 04 June 2019}

\section{References}

1. Hu YY, Lian QW, Lin ZH, Zhong J, Xue M, Wang LJ. Diagnostic performance of magnifying narrow-band imaging for early gastric cancer: a metaanalysis. World J Gastroenterol. 2015;21:7884-94 PubMed. https://www.ncbi. nlm.nih.gov/pubmed/?term=26167089 Accessed 10 Jan 2019.

2. Nakao M, Yoshida S, Tanaka S, Takemura Y, Oka S, Yoshihara M, et al. Optical biopsy of early gastroesophageal cancer by catheter-based reflectance-type laser-scanning confocal microscopy. J Biomed Opt. 2008;13:054043 PubMed. https://www.ncbi.nlm.nih.gov/pubmed/?term=19021423 Accessed 10 Jan 2019.

3. Otsuka Y, Niwa Y, Ohmiya N, Ando N, Ohashi A, Hirooka Y, et al. Usefulness of magnifying endoscopy in the diagnosis of early gastric cancer. Endoscopy. 2004;36:165-9 PubMed. https://www.ncbi.nlm.nih.gov/pubmed/ ?term=14765314 Accessed 10 Jan 2019.

4. Zhao Z, Yin Z, Wang S, Wang J, Bai B, Qiu Z, et al. Meta-analysis: the diagnostic efficacy of chromoendoscopy for early gastric cancer and premalignant gastric lesions. J Gastroenterol Hepatol. 2016;31:1539-45 PubMed. https://www.ncbi. nlm.nih.gov/pubmed/?term=26860924 Accessed 10 Jan 2019

5. Ono H, Kondo H, Gotoda T, Shirao K, Yamaguchi H, Saito D, et al. Endoscopic mucosal resection for treatment of early gastric cancer. Gut. 2001;48:225-9 PubMed. https://www.ncbi.nlm.nih.gov/pubmed/?term= 11156645 Accessed 10 Jan 2019.

6. Isomoto H, Shikuwa S, Yamaguchi N, Fukuda E, Ikeda K, Nishiyama H, et al. Endoscopic submucosal dissection for early gastric cancer: a large-scale feasibility study. Gut. 2009;58:331-6 PubMed. https://www.ncbi.nIm.nih.gov/ pubmed/19001058 Accessed 10 Jan 2019.

7. Kunisaki C, Akiyama H, Nomura M, Matsuda G, Otsuka Y, Ono H, et al. Surgical outcomes for early gastric cancer in the upper third of the stomach. J Am Coll Surg. 2005;200:15-9 PubMed. https://www.ncbi.n/m.nih. gov/pubmed/15631915 Accessed 10 Jan 2019.
8. De Ceglie A, Hassan C, Mangiavillano B, Matsuda T, Saito Y, Ridola L, et al. Endoscopic mucosal resection and endoscopic submucosal dissection for colorectal lesions: a systematic review. Crit Rev Oncol Hematol. 2016;104: 138-55 PubMed. https://www.ncbi.nlm.nih.gov/pubmed/27370173 Accessed 10 Jan 2019.

9. Lian J, Chen S, Zhang Y, Qiu F. A meta-analysis of endoscopic submucosal dissection and EMR for early gastric cancer. Gastrointest Endosc. 2012;76: 763-70 PubMed. https://www.ncbi.nlm.nih.gov/pubmed/22884100 Accessed 10 Jan 2019

10. Park YM, Cho E, Kang HY, Kim JM. The effectiveness and safety of endoscopic submucosal dissection compared with endoscopic mucosal resection for early gastric cancer: a systematic review and metaanalysis. Surg Endosc. 2011;25:2666-77 PubMed. https://www.ncbi.n/m.nih.gov/ pubmed/?term=21424201 Accessed 10 Jan 2019.

11. Saito $Y$, Emura F, Matsuda T, Uraoka T, Nakajima T, Ikematsu H, et al. A new sinker-assisted endoscopic submucosal dissection for colorectal cancer. Gastrointest Endosc. 2005;62:297-301 PubMed. https://www.ncbi.nlm.nih. gov/pubmed/?term=16046999 Accessed 10 Jan 2019.

12. Yamasaki $Y$, Takeuchi $Y$, Uedo N, Kato M, Hamada K, Aoi K, et al. Tractionassisted colonic endoscopic submucosal dissection using clip and line: a feasibility study. Endosc Int Open. 2016;4:E51-5 PubMed. https://www.ncbi. nlm.nih.gov/pubmed/?term=26793785\%5Buid\%5D Accessed 10 Jan 2019.

13. Imaeda $H$, Iwao Y, Ogata H, Ichikawa H, Mori M, Hosoe N, et al. A new technique for endoscopic submucosal dissection for early gastric cancer using an external grasping forceps. Endoscopy. 2006;38:1007-10 PubMed. https:// www.ncbi.nlm.nih.gov/pubmed/?term=16673308 Accessed 10 Jan 2019.

14. Chen PJ, Chu HC, Chang WK, Hsieh TY, Chao YC. Endoscopic submucosal dissection with internal traction for early gastric cancer (with video). Gastrointest Endosc. 2008;67:128-32 PubMed. https://www.ncbi.nlm.nih.gov/ pubmed/18054010 Accessed 10 Jan 2019.

15. Moher D, Liberati A, Tetzlaff J, Altman DG, Group P. Preferred reporting items for systematic reviews and meta-analyses: the PRISMA statement. Int Surg. 2010;8:336-41 PubMed. https://www.ncbi.nlm.nih.gov/pubmed/ ?term=20171303 Accessed 10 Jan 2019.

16. Higgins JP, Altman DG, Gotzsche PC, Juni P, Moher D, Oxman AD, et al. The Cochrane Collaboration's tool for assessing risk of bias in randomised trials. BMJ. 2011;343:d5928 PubMed. https://www.ncbi.nlm.nih.gov/pubmed/ 22008217 Accessed 10 Jan 2019.

17. Hozo SP, Djulbegovic B, Hozo I. Estimating the mean and variance from the median, range, and the size of a sample. BMC Med Res Methodol. 2005:5:13 PubMed. https://www.ncbi.nlm.nih.gov/pubmed/?term=15840177 Accessed 10 Jan 2019.

18. Ahn JY, Choi KD, Lee JH, Choi JY, Kim MY, Choi KS, et al. Is transnasal endoscope-assisted endoscopic submucosal dissection for gastric neoplasm useful in training beginners? A prospective randomized trial. Surg Endosc. 2013;27:1158-65 PubMed. https://www.ncbi.nlm.nih.gov/pubmed/?term= 23093232 Accessed 10 Jan 2019.

19. Koike Y, Hirasawa D, Fujita N, Maeda Y, Ohira T, Harada Y, et al. Usefulness of the thread-traction method in esophageal endoscopic submucosal dissection: randomized controlled trial. Dig Endosc. 2015;27:303-9 PubMed. https://www. ncbi.nlm.nih.gov/pubmed/?term=25357187 Accessed 10 Jan 2019.

20. Mori H, Kobara H, Nishiyama N, Fujihara S, Matsunaga T, Masaki T. Novel effective and repeatedly available ring-thread counter traction for safer colorectal endoscopic submucosal dissection. Surg Endosc Other Interv Tech. 2017;31:3040-7 PubMed. https://www.ncbi.nlm.nih.gov/pubmed/ ?term $=27858210$ Accessed 10 Jan 2019 .

21. Ritsuno H, Sakamoto N, Osada T, Goto SP, Murakami T, Ueyama H, et al. Prospective clinical trial of traction device-assisted endoscopic submucosal dissection of large superficial colorectal tumors using the S-O clip. Surg Endosc Other Interv Tech. 2014;28:3143-9 PubMed. https://www.ncbi.nlm. nih.gov/pubmed/?term=24879138 Accessed 10 Jan 2019.

22. Yamasaki Y, Takeuchi Y, Uedo N, Kanesaka T, Kato M, Hamada K, et al. Efficacy of traction-assisted colorectal endoscopic submucosal dissection using a clip-and-thread technique: a prospective randomized study. Dig Endosc. 2018;30:467-76 PubMed. https://www.ncbi.nlm.nih.gov/pubmed/ ?term=29424030 Accessed 10 Jan 2019

23. Yoshida M, Takizawa K, Suzuki S, Koike Y, Nonaka S, Yamasaki Y, et al. Conventional versus traction-assisted endoscopic submucosal dissection for gastric neoplasms: a multicenter, randomized controlled trial (with video). Gastrointest Endosc. 2018:87:1231-40 PubMed. https://www.ncbi.nlm.nih. gov/pubmed/?term=29233673 Accessed 10 Jan 2019. 
24. Ban $H$, Sugimoto M, Otsuka T, Murata M, Nakata T, Hasegawa H, et al. Usefulness of the clip-flap method of endoscopic submucosal dissection: a randomized controlled trial. World J Gastroenterol. 2018;24:4077-85 PubMed. https://www.ncbinlm.nih.gov/pmc/articles/PMC6148425/ Accessed 5 May 2019.

25. Gotoda T. Endoscopic diagnosis and treatment for early gastric Cancer. Cancer Rev Asia Pac. 2004;02:17-37. https://doi.org/10.1142/ S0219836304000378 World scientific. Accessed 10 Jan 2019.

26. Xie X, Bai JY, Fan CQ, Yang X, Zhao XY, Dong H, et al. Application of clip traction in endoscopic submucosal dissection to the treatment of early esophageal carcinoma and precancerous lesions. Surg Endosc Other Interv Tech. 2017;31:462-8 PubMed. https:/www.ncbi.nlm.nih.gov/pubmed/ ?term=27126625 Accessed 10 Jan 2019

27. Ohata K, Fu K, Sakai E, Nonaka K, Tashima T, Minato Y, et al. Esophageal endoscopic submucosal dissection assisted by an Overtube with a traction forceps: an animal study. Gastroenterol Res Pract. 2016;2016:3186168 PubMed. https:/www.ncbi.nlm.nih.gov/pubmed/?term=27528866 Accessed 10 Jan 2019

28. Okamoto K, Muguruma N, Kitamura S, Kimura T, Takayama T. Endoscopic submucosal dissection for large colorectal tumors using a cross-counter technique and a novel large-diameter balloon overtube. Dig Endosc. 2012 24:96-9 PubMed. https://www.ncbi.nlm.nih.gov/pubmed/?term=22533761 Accessed 10 Jan 2019

29. Yoshida M, Takizawa K, Ono H, Igarashi K, Sugimoto S, Kawata N, et al. Efficacy of endoscopic submucosal dissection with dental floss clip traction for gastric epithelial neoplasia: a pilot study (with video). Surg Endosc. 2016; 30:3100-6 PubMed. https://www.ncbi.n/m.nih.gov/pubmed/?term= 26487208 Accessed 10 Jan 2019.

30. Matsumoto K, Nagahara A, Ueyama H, Konuma H, Morimoto T, Sasaki H, et al. Development and clinical usability of a new traction device "medical ring" for endoscopic submucosal dissection of early gastric cancer. Surg Endosc Other Interv Tech. 2013;27:3444-51 PubMed. https://www.ncbi.nlm. nih.gov/pubmed/?term=23525882 Accessed 10 Jan 2019.

31. Gotoda T, Friedland S, Hamanaka H, Soetikno R. A learning curve for advanced endoscopic resection. Gastrointest Endosc. 2005:62:866-7 PubMed. https://www.ncbi.nlm.nih.gov/pubmed/?term=16301027 Accessed 10 Jan 2019.

32. Matsuzaki I, Hattori M, Hirose K, Esaki M, Yoshikawa M, Yokoi T, et al. Magnetic anchor-guided endoscopic submucosal dissection for gastric lesions (with video). Gastrointest Endosc. 2018;87:1576-80 PubMed. https:// www.ncbi.nlm.nih.gov/pubmed/?term=29352971 Accessed 10 Jan 2019

33. Higuchi K, Tanabe S, Azuma M, Sasaki T, Katada C, Ishido K, et al. Doubleendoscope endoscopic submucosal dissection for the treatment of early gastric cancer accompanied by an ulcer scar (with video). Gastrointest Endosc. 2013;78:266-73 PubMed. https://www.ncbi.nlm.nih.gov/pubmed/ ?term=23472995 Accessed 10 Jan 2019.

\section{Publisher's Note}

>Springer Nature remains neutral with regard to jurisdictional claims in published maps and institutional affiliations.

Ready to submit your research? Choose BMC and benefit from:

- fast, convenient online submission

- thorough peer review by experienced researchers in your field

- rapid publication on acceptance

- support for research data, including large and complex data types

- gold Open Access which fosters wider collaboration and increased citations

- maximum visibility for your research: over $100 \mathrm{M}$ website views per year

At $\mathrm{BMC}$, research is always in progress.

Learn more biomedcentral.com/submissions 